\title{
Dinamika haji Indonesia sejak era kolonial dan problematika calon haji ilegal
}

\author{
Moh. Rosyid \\ Sekolah Tinggi Agama Islam Negeri (STAIN) Kudus \\ E-mail:mrosyid72@yahoo.co.id
}

DOI: 10.18326/ijtibad.v17i2.241-259

The number of Indonesian pilgrims every year is increasing. On the other hand, the allocation of the number of pilgrims to be dispatched is limited by the quota. This triggers the waiting list and the share of various hajj efforts despite the violation of the law. However, not pilgrims know that pilgrimage using other country's passport is a violation of Law No. 12 of 2006 on Citizenship and possible losing of one's nationality. From historical perspective, Muslims' pilgrim dated back from the 16th century. At that time, there was strong suspicion that upon returning from pilgrimage, Muslims tend to be "rebellious" and initiated movement against the Dutch colonial government. Thus, the Dutch made a strict regulation concerning the Hajj and scrutinized Muslims before pilgrimage, while staying in Mecca and after their return. Among the movement against the Dutch led by Muslim upon returning the Hajj was the Padri movement. Nowadays, the number of Muslims who intend to go Hajj is rising significantly, and the waiting list goes for 15 to 20 years. The long list caused some people to find a way to go for Hajj including manipulation of citizenship documents, such as using passport of other countries. In respond to this situation, the government tries to negotiate with the Saudi government to increase the Hajj quota for Indonesians. Another effort is borrowing the remaining quota of neighboring countries. There is also suggestion to close the Hajj registration for some time and the need to revise the Hajj Law.

Jumlah calon jemaah haji Indonesia tiap tahun semakin meningkat. Di sisi lain, alokasi jumlah calon jemaah haji yang diberangkatkan dibatasi dengan kuota. Hal ini pemicu terjadinya waiting list dan andilnya ragam upaya berhaji meski melanggar hukum. Akan tetapi, tidak semua calon jemaah haji mengetahui bahwa berhaji dengan paspor negara asing adalah pelanggaran UU Nomor 12 Tahun 2006 tentang Kewarganegaraan yang berimplikasi hilangnya kewarganegaraan seseorang. Bila dikilas balik, sejarah calon jemaah haji warga Nusantara sejak abad ke-16. Indikasi kuat bahwa sepulang berhaji, semangat nasionalisme beragama (Islam) untuk melawan penjajah (yang kafir) sebagai dalih kolonial Belanda mempersulit calon jemaah haji dari aspek birokrasi dan pemantauan khusus kolonial bagi jemaah tatkala akan berangkat, tatkala di Makkah, dan sepulang ke Tanah Air. Hal ini terbukti adanya gerakan Padri yang menumbuhkan semangat jihad melawan kolonial. Ragam upaya kolonial mempersulit calon 
ljtihad: Jurnal Wacana Hukum Islam dan Kemanusiaan, Volume 17, No. 2, Desember 2017: 241-259

jamaah haji, tidak menyurutkan calon jemaah haji berhaji. Dalam konteks kini, besarnya animo calon jemaah haji sehingga terjadi daftar tunggu yang menjenuhkan. Pelampiasan yang dilakukan sebagian warga adalah menggunakan jalur paspor dari negara manca, meski melanggar perundang-undangan. Inisiasi yang dilakukan pemerintah Jokowi-JK agar waiting list tidak kian parah adalah memohon pada pemerintah Arab Saudi agar kuota haji ditambah. Hal ini terealisasi pada tahun 2017. Ada pula upaya meminjam kuota haji negara tetangga yang tersisa, meski belum ditemukan titik temu. Hal yang perlu diwujudkan adalah memoratorium pendaftar calon haji dan perubahan substansi UU Haji yang berpeluang mengurangi waiting list.

Keywords: Haij; government regulation; history

\section{Pendahuluan}

Menunaikan haji bagi muslim di Indonesia tidak hanya semata-mata perjalanan spiritual, ada yang menganggap sebagai simbol status sosial agar dilegitimasi oleh lingkungannya sebagai orang mampu secara ekonomi dan taat beragama. Besarnya animo berhaji juga dialami di negara tetangga, sebagaimana mencuat dalam Forum Menteri Agama Brunai Darussalam, Indonesia, Malaysia, dan Singapura (Mabims) ke-17 di Malaysia Selasa 6 Desember 2016. Di negara tersebut antrian/menunggu berhaji pascamendaftar lama/panjang juga. Di Indonesia terlama 42 tahun (di wilayah Sulawesi Selatan) dan terpendek 9 tahun, di Malaysia ada yang mengantri selama 93 tahun, di Singapura selama 35 tahun, dan di Brunai Darussalam selama 3-4 tahun. Panjangnya antrean seiring kebijakan pemerintah Arab Saudi memotong kuota haji negara pengirim jamaah sebesar 20 persen. Kuota normal Indonesia adalah 211 ribu yang terkurangi 42.200 jamaah setiap tahun sejak 2013, Malaysia dalam empat tahun kuotanya berkisar 22 ribu, Singapura 680 jamaah, dan Brunai hanya 300 jamaah yang terkurangi.

Di tengah tingginya animo calon haji di Indonesia, ada sembilan hal yang disoroti Komisi Pengawas Haji Indonesia (KPHI) dalam penyelenggaraan haji dari tahun ke tahun, yakni 1) pengawasan organisasi, tata kerja, dan petugas, 2) pengawasan aspek administrasi dan keuangan, 3) pengawasan pelaksanaan bimbingan ibadah, 4) pelayanan akomodasi, 5) pelayanan transportasi, 6) pelayanan konsumsi, 7) pelayanan kesehatan, 8) pengawasan dari aspek perlindungan dan pengamanan jamaah, dan 9) pengawasan terhadap penyelenggaraan haji khusus dan umrah. Kesembilan poin tersebut yang dilaporkan Ketua KPHI Samidin Nashir pada Presiden Jokowi, Selasa 14 Juni 2016. 
Hasil rekomendasi yang perlu segera ditata adalah 1) perlunya reformasi dalam penyelenggaraan haji meliputi aspek penyelenggaraan, tata kelola keuangan dan aspek operasional pelayanan, 2) berkaitan dengan masalah kelembagaan KPHI, yakni perlunya restrukturisasi panitia penyelenggara ibadah haji (PPIH) dan petugas yang profesional, 3) aspek administrasi dan keuangan perlu kesiapan dari Kemenag Kabupaten/Kota hingga pusat, dan 4) dana haji untuk dikelola secara profesional. Perlu pula memahami saran pengamat haji, Dadi Darmadi bahwa pelaksanaan haji di Makkah rawan pungli di banyak sektor pelayanan jemaah, yakni di bus salawat yang melayani transportasi jemaah dari pemondokan menuju Masjidil Haram pergi-pulang. Sesuai aturan Kemenag, bus tersebut gratis. Dengan diterbitkannya Kepres Nomor 74 Tahun 2017 tanggal 7 Juni tentang Pengangkatan Keanggotaan Dewan Pengawas Haji dan Anggota Badan Pelaksana Haji diharapkan kinerja penyelenggara haji makin baik.

Meraih status berhaji dengan ragam cara, meski belum memiliki dana cukup berupaya dengan model arisan haji, bagi yang siap dana memaksakan diri untuk berangkat haji meski melanggar perundang-undangan dengan cara menggunakan paspor negara lain untuk berhaji ke Tanah Suci. Obsesi besar tapi tidak tahu bagi calon jemaah haji dimanfaatkan oleh pihak yang ingin menumpuk pundi rupiah dengan kemudahan dan lekas berangkat haji tanpa daftar tunggu (waiting list). Hal ini menjadi kajian menarik agar tidak lagi terulang kesalahan bahwa ibadah haji harus menaati aturan syarak dan hukum positif. Bila dikilas balik, awal mula warga Nusantara berhaji perlu didedahkan agar terpetakan fase awal dan kondisi kini perihal animo muslim Nusantara (Indonesia) berhaji. Dengan paparan tersebut, permasalahannya adalah bagaimana pelayanan dan birokrasi haji era kolonial?, mengapa berhaji era kolonial dipersulit? faktor apa saja yang menjadi pendorong calon jamaah haji Indonesia menggunakan paspor fiktif?

Penelitian ini merupkana penelitian literer. Sumber data banyak diperoleh dari pemberitaan media massa, baik majalah maupun Koran. Analisis data yang digunakan adalah deskriptif kualitatif. Teknik penelitiannya studi kasus, yakni dalam hal ini penggunaan paspor negara asing (Filipina) oleh para calon jemaah haji Indonesia tahun 2016 M/1437 H. 
ljtihad: Jurnal Wacana Hukum Islam dan Kemanusiaan, Volume 17, No. 2, Desember 2017: 241-259

\section{Landasan teori}

Sejarawan berpendapat bahwa berdirinya kota Makkah karena drama kosmik ketika Allah menunjuk Adam sebagai khalifah di bumi. Saat itu malaikat meremehkan Nabi Adam, tetapi Allah menegaskan bahwa Sesunggubnya Aku mengetabui apa yang tidak kalian (Malaikat) ketabui. Sejak itu para malaikat tunduk pada Nabi Adam dan bertawaf pada Allah di Arsy. Para Malaikat diinstruksikan-Nya untuk membuat area tawaf di bumi sebagaimana yang terdapat di Arsy dan Baitul Makmur. Malaikat memilih bumi sebagai tempat tawaf yakni di Makkah. Makkah diciptakan Allah sebagai tempat atau poros antara Arsy dan Baitul Makmur dua ribu tahun sebelum Nabi Adam AS diturunkan di bumi. Makkah merupakan kota istimewa, sebagaimana pesan al-Balad:1-3, al-Isra:1, dan an-Naml: 91. Makkah mendapat julukan haramain (Makkah-Madinah) kota mulia, dan al-mukarramah (kota yang dimuliakan). Dalam al-Quran disebut ummul qura (ibu dari negeri-negeri), baramun amin (kota suci nanaman), Q.S: al-Qashash:57; al-haram (suci), dan al-balad (negeri).

Di Kota Makkah terdapat kakbah, yakni berarti kubus (bangunan segi empat yang sama panjang, lebar, dan tingginya) terdiri dari marmer dengan ketinggian kira-kira $25 \mathrm{~cm}$, lebar $30 \mathrm{~cm}$. Kakbah terbuat dari batu besar yang berwarna biru dari gunung di sekitar Makkah. Nama lainnya adalah baitullah karena berada di dalam Masjid al-Haram dan berkaitan dengan ibadah, seperti tawaf, sa'i, umrah, haji, salat, dan doa lainnya. Disebut pula baitul atiq (rumah kemerdekaan) karena dapat membebaskan manusia dari dosa bila bertaubat. Bermakna pula kiblat atah kiblah yakni arah salat muslim sedunia (Atjeh, 1993: 41).

Teori lainnya adalah fungsi dan peran agama ditinjau dari kajian sosiologi adalah fungsi manifest (disadari dan biasanya merupakan tujuan yang ingin dicapai oleh pemeluk agama) dan fungsi latent, yakni fungsi tersembunyi maksudnya kurang disadari pemeluk agama karena fungsi sampingan (Ishomuddin, 2002: 50). Dengan fungsi tersebut, agama bermakna dalam pengalaman pemeluknya. Agama memiliki makna komprehensif dalam kehidupan pemeluknya (Raho, 2013: 78). Adapun sikap beragama dibuktikan dengan mendekatkan diri pada Tuhan karena multifaktor, yakni sosial (pendidikan dari orangtua, tradisi sosial, sikap dalam lingkungan), alami (hadirnya keindahan, keselarasan yang dirasakan dalam dunia nyata), intelektual (memegang kuat kepercayaan dalam proses berpikir untuk alasan pembenar), afektif/emosional (pengalaman emosional bagian dari perilaku beragama dapat 
memperkuat agamanya), dan kebutuhan yang tak terpenuhi (Rohmah, 2013: 57).

Perkembangan keagamaan seseorang ditentukan pula pada usianya. Pada usia dewasa, kegiatan keagamaan berkorelasi dengan tingkat pemenuhan naluri di balik perilaku beragama (Arifin, 2008:110). Perkembangan beragama pada dewasa sebagai sikap pemenuhan jati diri, jalan hidup, dan tanggung jawab. Sikap beragama ditentukan oleh tiga komponen psikologis, yakni kognisi, afeksi, dan konasi. Ketiganya sebagai bagian yang menentukan sikap seseorang terhadap suatu obyek kongkrit atau abstrak dan dasar bersikap (Jalaluddin, 2009: 25).

Berhaji merupakan bukti ketaatan hamba pada perintah Tuhannya dan hukum negara. Persoalannya, berhaji memerlukan pengetahuan yang tidak hanya aspek syar'i saja, perlu pula memahami aturan yang berkait dengan birokrasi yang berhubungan dengan dua negara (negara calon jemaah haji dan negara tempat haji). Dengan demikian perlu memahami visa dan paspor.

Berdasarkan Keputusan Presiden RI Nomor 21 Tahun 2016 tentang Biaya Penyelenggaraan Ibadah Haji (BPIH) Tahun 2016 M/1437 H tanggal 13 Mei 2016 antar 12 embarkasi berbeda-beda jumlah pembayaran tiap calon jamaah. Rata-rata Rp 34.641 .304 atau 2.585 dollar AS dengan estimasi per dollar AS Rp 13.400. Biaya meliputi biaya penerbangan, pemondokan di Makkah, dan biaya hidup. Dibanding antara haji reguler dengan haji plus, perbedaan fasilitas berupa masa haji yang plus hanya 25/27 hari, sedangkan yang regular 38/40 hari, fasilitas hotel lebih mewah bagi yang plus, jarak ke Madinah, Arafah, dan lainnya dari maktab (pemondokan) lebih dekat, dan makan secara prasmanan bagi yang plus.

\section{Napak tilas sejarah haji era kolonial}

Dalam catatan sejarah, orang Indonesia yang pertama kali berhaji tertuang dalam naskah Carita Parabiyangan (naskah kuno berbahasa Sunda yang ditulis pada awal abad ke-16) dialah Bratalegawa. Ia putra kedua Prabu Guru Pangandiparamarta Jayadewabrata atau sang Bunisora, penguasa Kerajaan Galuh (1357-1371). Kerajaan Galuh merupakan kerajaan Sunda di Pulau Jawa, wilayahnya terletak antara Sungai Citarum di sebelah barat dan Sungai Ci Serayu dan Cipamali (Kali Brebes) di sebelah timur. Kerajaan Galuh meneruskan Kerajaan 
ljtihad: Jurnal Wacana Hukum Islam dan Kemanusiaan, Volume 17, No. 2, Desember 2017: 241-259

Kendan di bawah kekuasaan Tarumanagara. Raja Tarumanagara wafat tahun 669 M yang berkuasa sejak tahun $666 \mathrm{M}$.

Hubungan Makkah dengan Nusantara dibuktikan pada 1048/1638 penguasa Banten di Jawa Barat, Abd Qadir (berkuasa 1037-1063/1626-1651) mendapat gelar sultan dari Syarif Makkah sebagai hasil misi khusus yang dikirimkannya ke Tanah Suci. Sultan Banten juga menerima bendera dan pakaian suci (bekas jejak kaki nabi) dari penguasa Haramayn (Azra, 1998:55). Menurut Putuhena, penduduk Nusantara yang pertama kali menunaikan ibadah haji bukanlah jamaah haji yang bertujuan utama/awal dari Tanah Air. Akan tetapi, mereka yang berdagang, utusan sultan, dan musyafir yang menuntut ilmu ke Hijaz sekaligus berhaji ke Tanah Suci sejak tahun 1503 M (abad ke-16). Perjalanan mereka dengan kapalnya sendiri yang berlabuh di Jeddah (sebagai pelabuhan niaga, bukan pelabuhan haji). Sosok Nurullah (Syarif Hidayatullah, Sunan Gunung Jati) dari Pasai (yang ditaklukkan Portugis tahun 1521) untuk ke Makkah selama tiga tahun dimanfaatkan pula mengaji dan sekaligus berhaji. Tujuan utama ke Makkah adalah meminta bantuan Kerajaan Turki Utsmani (yang menguasai Makkah) agar mengusir Portugis dari Pasai (2007: 106-107). Dalam perkembangannya, pada abad ke-16 kapal Nusantara buatan Jepara mengarungi Samudera Hindia yang transit di Aceh dan berlabuh di Jazirah Arab. Mereka melanjutkan pelayaran hingga ke India, Hadramaut, Yaman, dan Jeddah dengan waktu tempuh hingga setengah tahun sekali jalan. Pada abad ke-17 dengan terbukanya jalur Samudera Hindia hingga Laut Merah dan Teluk Persia maka jamaah haji kian meruah didominasi kapal Belanda. Akan tetapi, Belanda menghentikan pengangkutan dengan Bessluit van Agustus 1716. Para jamaah haji selanjutnya mengandalkan kapal niaga secara sembunyi-sembunyi. Pada 1803 terdapat tiga jamaah haji asal Minangkabau yang mengembangkan gerakan Padri untuk memurnikan ajaran Islam di Nusantara. Belanda mencurigai sebagai gerakan perlawanan sehingga keberangkatan calon jamaah haji makin dipersulit. Pada 1825 Belanda mengeluarkan ordonansi, imbasnya biaya haji sangat tinggi yang mencapai 110 gulden dan mengawasi aktivitas jamaah selama di Makkah. Besarnya animo jamaah haji, kapal Arab dan Inggris ikut terlibat berbisnis pelayaran yang semula kapal layar diganti kapal api.

Sejak dibukanya Terusan Suez di Mesir tahun 1869, minat berhaji bangsa Indonesia meningkat. Jemaah haji pun dicurigai membawa ajaran Islam setiba di Tanah Air dengan 
mengobarkan semangat nasionalisme melawan penjajah. Sehingga Belanda membuka konsulat di Jeddah pada 1872 untuk mengawasi gerak jemaah haji Indonesia bila berinteraksi dengan muslim dunia. Mereka di Makkah menerima doktrin perlawanan terhadap kolonial yang identik beragama Kristen. Pada 1866 terdapat 2.000 jamaah dan pada 1896 jumlahnya menjaddi 11.788 orang. Pengawasan jamaah haji Tanah Air selain di Makkah, juga di Kairo Mesir, Kalkutta India, dan Singapura. Untuk mengoptimalkan pengawasan pada jamaah haji setelah kembali di Tanah Air, Belanda mengangkat penghulu sebagai pegawai negeri untuk membantu bupati mengawasinya. Kebijakan makin diperketat Belanda dengan memonopoli pelayaran pada tiga kongsi, Rotterdamsche Llyod, Stoomvaartmatschappij Nederland, dan Stoomvaartmatschappi Oceaan pada 1873. Pada 1874 diterbitkan peraturan oleh Belanda agar hanya yang mampu membeli tiket pergi-pulang dan seizin tertulis dari pangreh praja setempat yang diizinkan berlayar agar tak lama tinggal di Makkah. Setiba di Jeddah Makkah dan sepulang di Tanah Air jamaah melapor pada konsulat Belanda. Pada 1884, dibuatlah kartu pas perjalanan yang memuat jenis kelamin, umur, tinggi badan, bentuk hidung, mulut, dagu, jenggot atau kumis.

\section{Haji dan nasionalisme}

Pada 1805 atas prakarsa Angku Gapuak (saudagar), Angku Syekh Haji Umam (tokoh masyarakat), dan Angku Syekh Kapalo Koto (ulama) memanfaatkan Masjid Ganting sebagai embarkasi. Pada 1855 masjid ini digunakan embarkasi sebelum keberangkatan melalui Pelabuhan Emmahaven (kini disebut Teluk Bayur). Pelabuhan itu berfungsi sebagai penghubung daratan di Samudera Hindia, Laut Merah, dan Teluk Persia. Pada 1918 Masjid dijadikan sentra pergerakan Kaum Padri melawan Belanda. Pada 1921 Abdul Karim Amrullah (bapaknya Hamka) mendirikan Sekolah Thawalib untuk pengajaran agama di lingkungan masjid. Para alumni mendirikan Persatuan Muslim Indonesia (Permi) sebagai cikal bakal Masyumi. Pada 1932 masjid dijadikan jambore pertama gerakan kepanduan Muhammadiyah Hizbul Wathan.

Kecurigaan Belanda pada para haji makin tinggi, sehingga dipersulit dan dibatasi ruang geraknya di Makkah, disterilkan dari pola pikir nasionalisme setelah kedatangan dari Makkah, dan sebelum bergabung dengan warga tetangga di kampung dengan pola karantina, dan 
ljtihad: Jurnal Wacana Hukum Islam dan Kemanusiaan, Volume 17, No. 2, Desember 2017: 241-259

sebagainya. Dengan demikian, menandakan bahwa sulitnya orang berhaji pada masa lalu penuh liku dan kecurigaan dari kolonial. Imbasnya, bila orang mampu haji (pada masa lalu) diberi "tanda" berupa nama yang diawali titel "haji" dan kehidupannya masa kolonial menjadi pantauan khusus.

Belanda menyadari bahwa imbas interaksi jamaah haji dengan berbagai bangsa di Makkah menjadi pekerjaan ekstra. Hal ini berawal dari terjadinya Perang Padri. Jauh sebelumnya, orientalis dan Islamolog terkemuka, Christian Snouck Hurgronje seorang Kristen beraksi di Indonesia. Snouck datang di Indonesia untuk memantau Islam di Aceh dan kemudian di Batavia. Ia memahami bahwa denyut nadi nasionalisme keislaman dan kebangsaan jamaah haji asal Indonesia setiba di Tanah Air ditanam dari Makkah. Snouck menemukan pola kebijakan pemerintahan Hindia Belanda untuk menghadapi umat Islam Indonesia. Bagi Snouck, musuh kolonialisme bukanlah Islam sebagai agama, tapi Islam sebagai doktrin politik. Snouck meraih gelar doktor dengan disertasi Het Mekaansche Feest (Perayaan di Makkah atau ibadah haji). Snouck datang di Hindia Belanda (Indonesia) tahun 1889 ditunjuk sebagai penasehat pada Kantor Urusan Orang Pribumi dan Arab (Kantoor voor Inlandsche Zaken) pada era Jepang berganti nama Shumubu, cikal bakal Kementerian Agama RI.

Pada 1803 ada tiga jamaah haji Minangkabau mengembangkan Gerakan Padri untuk memurnikan Islam di Nusantara. Belanda mencurigai sebagai gerakan perlawanan sehingga jamaah haji makin dipersulit. Pada 1825 Belanda mengeluarkan ordonansi (peraturan pemerintah), imbasnya biaya haji makin tinggi mencapai 110 gulden dan di Makkah diawasi aktivitasnya. Besarnya animo berhaji, kapal Arab dan Inggris ikut berbisnis pelayaran, semula kapal layar diganti kapal api. Kecurigaan nasionalisme melawan penjajah itulah Belanda membuka konsulat di Jeddah pada 1872 untuk mengawasi gerak jamaah haji Indonesia bila berinteraksi dengan muslim di Makkah. Doktrin perlawanan kolonial karena penjajah non-muslim.

Pada 1866 terdapat 2.000 jamaah dan pada 1896 menjadi 11.788 orang. Kebijakan makin ketat, Belanda monopoli pelayaran tiga kongsi, Rotterdamsche Llyod, Stoomvaartmatschappij Nederland, dan Stoomvaartmatschappi Oceaan pada 1873. Pada 1874 diterbitkan peraturan oleh Belanda agar hanya yang mampu membeli tiket pergi-pulang dan seizin tertulis dari pangreh praja setempat yang diizinkan berhaji. Setiba di Jeddah Makkah dan sepulang di tanah Air jamaah melapor pada konsulat Belanda. Pada 1884, dibuat pas perjalanan memuat jenis 


\section{Dinamika haji Indonesia sejak era kolonial dan problematika calon haji ilegal (Moh. Rosyid)}

kelamin, umur, tinggi badan, bentuk hidung, mulut, dagu, jenggot atau kumis.

Pengarantinaan dirasa tak manusiawi sehingga pada 1912 Perserikatan Muhammadiyah mendirikan biro penolong haji. Pada 1922 upaya melindungi jamaah haji diwujudkan dengan diperbolehkannya warga pribumi mendirikan pengangkutan jamaah haji. Pada 1926 ulama berkumpul di Surabaya memutuskan mengirim delegasi ke Arab untuk mendapat informasi persyaratan berhaji. Pada 1933 embarkasi di Pulau Onrust dipindah ke Pelabuhan Tanjungpriok agar lebih manusiawi. Tempat yang serupa Onrust dibuat Belanda di Masjid Raya Ganting Padang Sumbar, embarkasi haji pertama di wilayah Sumatera bagian tengah. Pada 1805, prakarsa Angku Gapuak (saudagar), Angku Syekh Haji Umam (tokoh masyarakat), dan Angku Syekh Kapalo Koto (ulama) masjid digunakan pada 1810. Pada 1855 masjid untuk embarkasi melalui Pelabuhan Emmahaven (Teluk Bayur). Pelabuhan berfungsi penghubung daratan di Samudera Hindia, Laut Merah, dan teluk Persia. Pada 1918 Masjid dijadikan sentra pergerakan Kaum Padri melawan Belanda.

Adanya Perang Padri sangat dipengaruhi doktrin haji dan doktrin keislaman di Makkah. Dalam catatan sejarah, Indonesia memiliki ulama berkaliber dan kiprahnya menjadi rujukan dunia. Para ulama itu menimba ilmu di Timur Tengah terutama di Haramain (MakkahMadinah), Kairo Mesir, dan Yaman. Selanjutnya mereka membentuk jejaring karena menimba ilmu di mancanegara. Pertimbangan belajar di Timur Tengah karena otentisitas sumber ilmu keislaman dan well come-nya bangsa Arab dengan datangnya muslim mancanegara. Proses pembelajaran di Masjidil Haram, Bait al-Shaikh atau rubat (rumah guru mengaji), madrasah, dan al-Jami'ah dengan metode pembelajaran halaqah.

Pembelajaran di rubat yang pengajarnya tak mendapat izin oleh pengelola masjid AlHaram karena bukan penduduk asli atau karena terlalu tua sehingga secara fisik tak mampu. Pembelajaran di madrasah didirikan oleh perorangan atau paguyuban warga asing yang mutasi kewarganegaraan (taba'iya) (Rosyid, 2014). Sejarawan membuat periodisasi kajian oleh ulama Nusantara di Tanah Haramain meliputi tiga babakan (1) abad ke-17 hingga akhir abad ke-19 wacana tradisionalisme dan neosufisme; (2) abad ke-20 hingga 1950-an di Haramain ada 2 kelompok, yakni tradisionalis dan reformis. Era tradisionalis mendirikan Madrasah Shaulatiyah hingga menjadi Madrasah Darul 'Ulum yang dimotori Syekh Yasin. Era reformis mendirikan Madrasah Indunisiyyin diprakarsai orang Indonesia yang bergelar 
ljtihad: Jurnal Wacana Hukum Islam dan Kemanusiaan, Volume 17, No. 2, Desember 2017: 241-259

L.c perdana dari Universitas Al-Azhar yakni Syekh Janan Thayib. Madrasah tersebut pudar semenjak PD II, (3) dekade 1960-an hingga sekarang. Masa ini, era reformis mengalami kekalahan karena bertolak belakang dengan ideologi Bani Saud di Arab Saudi (Rosyid, 2014).

\section{Calon haji Indonesia dengan paspor Filipina}

Sebanyak 177 warga Negara Indonesia (WNI) yang berencana menunaikan ibadah haji tahun 2016 menggunakan paspor Filipina. Mereka sebagai korban penipuan sindikat jamaah haji yang sepenuhnya diatur oleh agen biro perjalanan/travel dari Tanah Air ke Filipina selanjutnya ke Tanah Suci. Dari 177 WNI yang terungkap 19 Agustus 2016 oleh aparat hukum Filipina, 139 orang sempat ditahan di camp Bagong Diwa, Taquiq City Filipina kemudian diserahkan pada Kedutaan Besar RI (KBRI) di Filipina. Akan tetapi 38 WNI masih ditahan pemerintah Filipina karena sebagai penipu agen biro perjalanan. Polri mengirimkan tim untuk memeriksa tindak pidana agen biro perjalanan haji untuk menelusuri peran koordinator yang mendampingi rombongan haji, yakni koordinator dari Jakarta dan Makassar (Kompas, 27 Agustus 2016).

Pemerintah RI (4 September 2016) belum bisa memastikan kapan mereka akan dipulangkan karena aparat hukum Filipina masih melakukan pendalaman informasi terkait kasus visa palsu dengan kuota pemberangkatan haji Filipina. WNI yang menggunakan paspor Filipina ditangkap Jumat 19 Agustus 2016. Rencana keberangkatan mereka ke Tanah Suci diketahui otoritas Filipina sehingga mereka ditahan di Manila. Berdasarkan pemeriksaan awal, ratusan WNI itu diduga sebagai korban penipuan. Polda Sulawesi Selatan memeriksa dua biro perjalanan haji yang memberangkatkan 102 dari 177 calon haji asal Indonesia melalui Filipina (Kompas, 31 Agustus 2016).

Agusnadi 38 tahun WNI asal Kabupaten Wajo Sulawesi mengaku membayar 9.500 dollar Amerika Serikat (AS) atau sekitar 126 juta ke sebuah biro perjalanan haji di Wajo yang mengurus keberangkatannya. Ia tahu pemberangkatan melalui Filipina, tapi tidak memahami tindakannya dikategorikan ilegal. Setelah kasus terungkap, biro perjalanan menjanjikan mengembalikan uangnya 100 persen. Ia berharap pada pemerintah agar diprioritaskan berangkat haji tahun depan (2017). Kepulangan mereka dari Filipina untuk kembali ke Tanah 


\section{Dinamika haji Indonesia sejak era kolonial dan problematika calon haji ilegal (Moh. Rosyid)}

Air (tidak jadi berangkat haji) didampingi Dubes Indonesia untuk Filipina Johny Lumintang diterima Gubernur Sulsel Syahrul Yasin Limpo dengan pesawat Air Asia TX 892 yang dicarter Kemenlu (Kompas, 5 September 2016).

Majalah Tempo edisi 5-11 September 2016 mewartakan, Saiful Anam warga Pasuruan Jawa Timur terkaget setelah melihat sang ibunya, Sumiati ditahan petugas imigrasi Bandara Internasional Ninoy Aquino, Manila, 19 Agustus 2016 via televisi. Sebelumnya sang ibu Saiful ia antar ke Bandara Juanda Sidoarjo Jawa Timur untuk berangkat haji melalui Filipina. Saiful merasa ada kejanggalan tatkala mendaftarkan sang ibu ke Kelompok Bimbingan Ibadah Haji (KBIH) Arafah, Pasuruan Januari 2016. KBIH menjanjikan sang ibu Saiful berangkat haji tahun 2016 dengan ongkos Rp 150 juta. Padahal, bila mengikuti jalur reguler (via Kemenag RI) membayar Rp 35 juta, meski harus waiting list/daftar tunggu (di Sulawesi Selatan hingga 30 tahun dan di Jawa hingga 20 tahun lagi diberangkatkan).

Sumiati (72 tahun) mengikuti bimbingan haji bulan Maret 2016 di KBIH Arafah (yang memberangkatkan 12 calon haji) selama 10 hari, tanpa sepengetahuan keluarganya dan diajak “jalan-jalan” oleh KBIH ke Filipina. Hal serupa dialami Nurdin bin Palla, 50 tahun, warga Kelurahan Pompanua, Kecamatan Ajangale, Kabupaten Bone, Sulawesi Selatan. Ia berhaji melalui biro perjalanan PT Aulad Amin di Makassar membayar Rp 135 juta. Ia tak tahu bila berangkat haji melalui negara asing itu ilegal.

Awal mula terdeteksinya calon jemaah haji Indonesia via Filipina di Bandara Filipina karena (1) jemaah Filipina lazimnya bercelana cingkrang, sedangkan asal Indonesia tidak bercelana cingkrang, bahkan ada yang membawa sarung dan memakai peci (ciri khas orang Indonesia). Bahasa Filipina yang digunakan adalah Tagalog, sedangkan jemaah calon haji asal Indonesia tak bisa berbahasa Tagalog. Bahkan ada yang berteriak "I am Indonesian" di antara jemaah tatkala pihak Bandara menanyakan identitasnya. Dengan kecurigaan pihak Bandara Filipina maka jemaah yang sudah di pesawat (menuju ke Saudi Arabia) sebelum take off diturunkan pihak bandara dan diamankan. Ada 99 perempuan dan 78 lelaki, 44 di antaranya berusia di atas 60 tahun, dari Sulawesi Selatan ada 101 orang, dari Jawa Tengah 19 orang, Kalimantan Timur 13 orang, Jawa Timur 12 orang, Kalimantan Utara 7 orang, Jakarta dan Jawa Barat masing-masing 6 orang, Banten dan Jambi masing-masing 4 orang, Yogyakarta 2 orang, dan Sumatera Utara, Kepulauan Riau, dan Sulawesi Barat masing- 
ljtihad: Jurnal Wacana Hukum Islam dan Kemanusiaan, Volume 17, No. 2, Desember 2017: 241-259

masing 1 orang. Kejadian ini merupakan hal yang pertama kalinya calon haji asal Indonesia tertangkap secara massal di Filipina.

Selanjutnya, masih dalam laporan Majalah Tempo, kesuksesan jemaah haji asal Indonesia yang berangkat tahun 2015 melalui Filipina dialami Sumarjo warga Tarakan Kalimantan Utara. Awalnya menyamar sebagai wisatawan meski tujuan utamanya mengurus KTP sementara Filipina. KTP sebagai syarat mendapatkan paspor Filipina yang dibantu perantara asal Filipina. Sumarjo berganti nama menjadi Muhammad Rio. Ketika musim haji tiba pada Agustus 2015, Rio kembali berangkat ke Filipina. Di Bandara Soekarno-Hatta, Rio bertemu dengan sekitar 100 calon haji lain yang akan berangkat via Filipina. Setiba di Filipina, paspor dan visa sudah siap. Sebelum masuk Bandara Filipina, perantara lokal mengingatkan agar Sumarjo dan lainnya bersikap dan berpakaian layaknya orang Filipina. Di Arab Saudi bergabung dengan jemaah asal Filipina, meski ia lebih akrab mengobrol dengan jemaah asal Indonesia. Bila ada jemaah asal Filipina yang menanyakan pada Rio, mengapa lancar berbahasa Indonesia, Rio menjawab pernah kuliah di Yogyakarta. Sepulang dari Arab Saudi, Rio pulang via Filipina sebelum masuk Indonesia. Ongkos naik haji via Filipina tahun 2015 sekitar Rp 35 juta plus biaya pengurusan dokumen sekitar Rp 15 juta.

Pemilik KBIH Arafah, Nurul Huda mengungkapkan peran calo asal Filipina. Huda membayar USS 8.500 per calon haji, tiap calon jemaah dipungut oleh Huda sebesar USS 10 ribu. Para calo memiliki jaringan dengan tokoh muslim asal Filipina bernama Syekh Rosyidin. Rosyidin juga memfasilitasi keberangkatan 18 calon jemaah haji berasal dari Barru Sulawesi Selatan, di antaranya Machmud 54 tahun. Rumah Machmud juga dijadikan pendaftaran bagi calon jemaah yang diberangkatkan jaringan Syekh Rosyidin. Perkenalan Machmud dengan Rosyidin tatkala Rosyidin datang ke Barru bahwa dirinya bisa membantu kepada pihak yang mau berhaji dengan cepat via Filipina. Kuota haji di Filipina menurutnya ada 8.000 orang tapi hanya terisi 6.000 orang. Pada tahun 2014 ada 10 warga Barru yang mendaftar, tahun 2015 ada 20 orang, tahun 2016 ada 18 orang yang mendaftar dengan ongkos bervariasi dari Rp 110 juta hingga Rp 130 juta.

Tahun 2016 ada 12 pendaftar pada kloter ketiga yang tertangkap di Filipina. Untuk kloter pertama dan kedua lolos dan dapat berangkat ke Tanah Suci tahun 2016. Model pemberangkatan haji muslim Indonesia via Filipina menurut Gian warga Parung Panjang, 
Bogor sudah terjadi sejak 4 tahun lalu, yakni tahun 2012 (Majalab Tempo, edisi 5-11 September 2016).

\section{Kronologi pemberangkatan haji ilegal dan penindakan hukum}

Siti Aminah dan Karomisah berangkat haji melalui KBIH Fadlu Robbi milik Sugipah Zahroh warga Desa Kuwasen, Jepara, Jateng dengan membayar Rp 120 juta. Pada bulan Ramadan 2015, mereka mengurus visa dan paspor kewarganegaraan Filipina di Pati Jateng untuk keberangkatannya ke Filipina. Pertengahan Juli 2016, didampingi pembimbingnya terbang ke Filipina. Pihak keluarga Karomisah tak mengetahui bila paspor kewarganegaraan Filipina itu ilegal (karena WNI). Manasik haji pun dilaksanakan di Jepara bersama dengan jemaah haji reguler Kemenag. Rabu 17 Agustus 2016 malam, Karomisah diantar keluarga dan tetangga ke Bandara Ahmad Yani Semarang, bertemu dengan jemaah haji dari Jepara lainnya, paginya terbang ke Jakarta yang selanjutnya ke Filipina. Tatkala berangkat, Karomisah tidak membawa perlengkapan haji, sebab pakaian haji (ihrom, dll) dijanjikan disiapkan di Filipina. Tatkala tiba di Filipina, rombongan bertemu dengan pengelola biro di Filipina untuk menukar paspor dan visa wisata dengan paspor warga negara Filipina dan mendapat perlengkapan haji. Menjelang boarding pass, mereka ditahan otoritas Filipina (Murianews.Com, 27 Agustus 2016).

Awal September 2016 Polri mengembangkan kasus dugaan penipuan pemberangkatan haji yang dialami 177 WNI. Ada 9 di antaranya masih ditahan di Filipina untuk membantu mengungkapkan kasus karena mereka bisa berbahasa Inggris. Adapun 110 WNI sudah dipulangkan ke Tanah Air, yakni 1 orang ke Makassar Sulawesi Selatan, 1 orang ke Sulawesi Barat, 15 orang ke Kalimantan, dan 58 orang ke Jakarta. Ada 5 orang dari biro perjalanan yang dijadikan tersangka oleh Polri. Penyidik telah memeriksa 64 saksi, termasuk calon jamaah haji yang masih di Filipina (Kompas, 6 September 2016). Ada 168 dari 177 WNI calon jemaah haji yang ditahan otoritas Filipina dipulangkan ke Tanah Air setelah mendapatkan clearance dan supplementary guarantee letter dari otoritas Filipina untuk dideportasi hasil upaya KBRI. Ada 100 WNI yang diserahterimakan pada Pemda Sulawesi Selatan di Bandara Hasanuddinn, 68 WNI diserahkan KBRI kepada pemda masing-masing di Bandara Soekarno-Hatta Cengkareng, Tangerang (CNN Indonesia.com, 5 September 2016). 
ljtihad: Jurnal Wacana Hukum Islam dan Kemanusiaan, Volume 17, No. 2, Desember 2017: 241-259

Bareskrim Polri Jumat 9 September 2016 menetapkan 7 tersangka kasus dugaan pemalsuan paspor terhadap 177 WNI calon haji tersebut. Ketujuh tersangka merupakan pimpinan dari sejumlah agen pemberangkatan haji di Indonesia, yakni AS dan BDMW pemilik PT Ramana Tour menerima pembayaran haji khusus dari 38 korban dengan kerugian Rp 3,3 miliar; MNA merekrut 65 calon haji, keuntungannya Rp 6,3 miliar; MT dengan 21 korban dari Sulawesi yang rata-rata membayar Rp 150 juta per korban; F dan AH pimpinan PT Shafwah memberangkatkan 24 korban mendapat dana Rp 3 miliar; ZAP pimpinan PT Hade El Badr memberangkatkan 12 korban dan memperoleh dana Rp 2 miliar.

Para tersangka dijerat UU Nomor 8 Tahun 1999 tentang Perlindungan Konsumen, UU Nomor 13 Tahun 2008 tentang Penyelenggaraan Ibadah Haji, dan Pasal 378 KUHP tentang Tindak Pidana Penipuan. Menurut Kadiv Imigrasi Kanwil Kemenkumham Jakarta Yudanus Dekiwanto, tak ada pelanggaran imigrasi di Indonesia yang dilakukan 177 calon jemaah haji yang berangkat ke Filipina. Semua persyaratan administrasi untuk membuat paspor sudah terpenuhi. Hanya saja, mereka tak jujur dengan tujuannya berangkat ke Filipina dan dari Filipina ke mana. Waktu berangkat ke Filipina mereka menggunakan dokumen yang sah dan lolos pemeriksaan imigrasi. Namun, tersandung masalah ketika berada di Filipina karena paspor palsu yang disediakan oknum agen perjalanan illegal agar bisa berangkat ke Arab Saudi dari Filipina (Kompas.com, 22 September 2016).

Selasa, 13 September 2016 Polri menetapkan satu tersangka baru dalam kasus penipuan pemberangkatan calon haji yakni HR diduga sebagai pelaku utama penipuan calon haji. Ia mengatur seluruh proses perencanaan dari Indonesia hingga izin keluar dari Filipina menuju Arab Saudi. Ia mengoordinir lima biro perjalanan asal Indonesia yang merekrut dan memberangkatkan, keperluan jemaah di Filipina hingga kembali dari Saudi. Polisi juga memanggil tujuh tersangka lain untuk menjalani pemeriksaan perdana sebagai tersangka, yakni AS, BMDW, MT, ZAP, F alias H, AH, dan MNA. Mereka akan dijerat dengan Pasal 62 UU Nomor 8 Tahun 1999 tentang Perlindungan Konsumen, Pasal 63 dan 64 UU Nomor 13 Tahun 2008 tentang Penyelenggaraan Ibadah Haji, dan Pasal 378 KUHP dengan ancaman hukuman penjara 12 tahun (Kompas, 14 September 2016). Hingga ditulisnya naskah ini, penulis belum mendapatkan proses hukum akhir (sanksi hukum) bagi pelaku penipuan haji. 
Mengacu UU Nomor 12 Tahun 2006 tentang Kewarganegaraan Pasal 23 "WNI kehilangan kewarganegaraannya jika yang bersangkutan memperoleh kewarganegaraan lain atas kemauan sendiri, tidak menolak atau tidak melepaskan kewarganegaraan lain, mempunyai paspor atau surat yang bersifat paspor dari negara asing yang masih berlaku dari negara lain atas namanya. Warga negara yang menjadi warga negara lain tersebut kehilangan kewarganegaraan berlaku dengan sendirnya." Pasal 9 permohonan pewarganegaraan dapat diajukan oleh pemohon (mantan WNI yang ingin menjadi WNI lagi) dengan memenuhi persyaratan pada waktu mengajukan permohonan sudah bertempat tinggal di wilayah RI paling singkat 5 tahun berturut-turut atau paling singkat 10 tahun tidak berturut-turut. Bila mendapat kewarganegaraan RI, tak menjadi berkewarganegaraan ganda. Peraturan Pemerintah Nomor 2 Tahun 2007 tentang Tata Cara Memperoleh, Kehilangan, Pembatalan dan Memperoleh Kembali Kewarganegaraan RI pada Pasal 31 WNI dengan sendirinya kehilangan kewarganegaraannya karena memperoleh kewarganegaraan lain atas kemauannya sendiri, tidak menolak atau tidak melepaskan kewarganegaraan lain, secara suka rela mengangkat sumpah atau menyatakan janji setia kepada negara asing atau bagian dari negara asing tersebut, mempunyai paspor atau surat yang bersifat paspor dari negara asing yang masih berlaku dari negara lain atas namanya.

Pemerintah Filipina tak akan memidanakan jemaah tersebut karena mereka korban penipuan. Pemerintah RI pun tak memberlakukan Pasal 23 huruf H UU Nomor 12 Tahun 2006 tentang Kewarganegaraan. Pasal itu menyebutkan seseorang kehilangan kewarganegaraan jika mempunyai paspor atau surat yang bersifat paspor dari negara asing atas namanya. Mereka tak akan kehilangan kewarganegaraan RI. Hal ini dinyatakan Menkum HAM Yasonna H Laoly saat rapat dengar pendapat dengan Komisi III DPR RI Rabu 7 September 2016 (Kompas, 8 September 2016). Agen yang memberangkatkan calon jemaah haji tersebut asal Indonesia, yakni PT Taskiah, PT Aulad Amin, PT Aulad Amin Tours Makassar, Travel Shafwa Makassar, Travel Hade El Barde, KBIH Arafah, dan KBIH Arafah Pandaan.

Dalam kasus lain yang serupa, Polri menyelidiki 700 jemaah haji Indonesia ke Tanah Suci melalui Filipina dan menggunakan paspor Filipina (selain 177 calon jamaah WNI yang telah tertangkap). Polri bekerja sama dengan Kemenlu RI mengenai lolosnya ratusan WNI tersebut. Menlu RI Kamis 15 September 2016 menugaskan tim khusus untuk ke Manila Filipina 
ljtihad: Jurnal Wacana Hukum Islam dan Kemanusiaan, Volume 17, No. 2, Desember 2017: 241-259

mengantisipasi penanganan jemaah haji asal Indonesia yang sedang berhaji (sebelum pulang dari Arab Saudi) yang diperkirakan tiba di Filipina pada 18-30 September 2016. Tim yang diketuai Direktur Perlindungan WNI dan Badan Hukum Indonesia Kemenlu, Lalu M Iqbal telah bertemu dengan satgas dari Filipina (Kompas, 16 September 2016). Jauh sebelumnya, ada 229 WNI ditahan di rutan Arab Saudi menjelang wukuf pada ibadah haji 2016. Hal ini disebabkan tak memiliki izin haji dan sebagian berada di Tanah Suci lebih lama dari izin yang ada (overstay) karena awalnya untuk ibadah umrah (Suara Merdeka.com, 11 September 2016).

Dengan demikian, hal mendasar adalah bagi mubaligh atau pendakwah dalam memberi pemahaman kewajiban haji bagi muslim secara utuh, yakni orang yang mampu berhaji sebagaimana pesan al-Quran, sehingga tidak menjadi calon jemaah haji yang memaksakan diri.

\section{Problem solving}

Fakta terjadinya penggunaan visa fiktif dapat disikapi dengan memahami dan mengevaluasi untuk perbaikan atas UU dan peraturan pelaksanaannya. UU Nomor 17 Tahun 1999 tentang Penyelenggaraan Ibadah Haji diubah dengan UU Nomor 13 Tahun 2008. Pasal 28 penetapan kuota haji diatur dalam peraturan pemerintah (PP). PP selalu dinamis (mengalami perbaikan) karena dinamika penyelenggaraan haji. Dalam Peraturan Menteri Agama (PMA) Nomor 29 Tahun 2015 tentang Perubahan atas PMA Nomor 14 Nomor 2012 tentang Penyelenggaraan Ibadah Haji Reguler pada Pasal 3 (1) pendaftaran jemaah haji sepanjang tahun. Pasal 4 (1) b calon jemaah haji berusia minimal 12 tahun pada saat mendaftar. Pasal 15 (1) pemerintah wajib memberikan bimbingan kepada jemaah sebelum keberangkatan, selama dalam perjalanan, selama dan sampai dengan kepulangan ke Indonesia, ayat (2) bimbingan tersebut bagi jemaah haji yang berhak melunasi BPIH kuota musim haji tahun berjalan.

Catatan yang perlu didalami, pertama, Pasal 3 (1) pendaftaran jemaah haji sepanjang tahun. Pasal ini perlu diperbaiki dengan penutupan sementara pendaftaran (moratorium) hingga memungkinkan tak terjadi waiting list yang terjadi makin tahun makin banyak. Aspek lainnya dengan tak menumpuknya jumlah pendaftar calon jemaah haji maka moratorium pendaftaran calon jamaah haji sebuah keharusan, sebagaimana usulan Komisi Pemberantasan 
Korupsi (KPK) tahun 2014 yang tak direspon Kemenag. Dalih KPK, waiting list rentan terjadi korupsi. Semakin banyaknya pendaftar dan tak dibatasi, dikhawatirkan menggunakan jalan pintas. Meskipun, tak diterimanya calon pendaftar jemaah haji pun berpeluang terjadi persoalan, yakni berpeluang menggunakan jalan pintas pula, sebagaimana menggunakan visa fiktif. Akan tetapi, setidak-tidaknya, moratorium dan pemahaman pada publik tentang visa fiktif dapat mengurangi kesalahan.

Kedua, Pasal 4 (1) b calon jemaah haji berusia minimal 12 tahun pada saat mendaftar. Pasal ini pun perlu direvisi bahwa usia 12 tahun adalah masa anak/ remaja. Idealnya, pendaftar minimal berusia 18 tahun (usia non-anak). Bila pendaftar berusia minimal 18 tahun, jumlah calon jemaah yang menunggu pemberangkatan (waiting list pun) berkurang. Ketiga, Pasal 15 (1) pemerintah wajib memberi bimbingan kepada jemaah sebelum keberangkatan, selama dalam perjalanan, selama dan sampai dengan kepulangan ke Indonesia. Pasal ini hanya membatasi pada orang yang nyata-nyata akan berangkat haji untuk mendapatkan pemahaman tentang multiaspek haji. Idealnya pembekalan/pemberitahuan hal tersebut diberikan pula pada publik yang akan/ingin mendaftar, khususnya perihal tataadministrasi kependudukan dan administrasi kunjungan ke luar negeri. Terjadinya visa fiktif karena mayoritas tidak mengetahui bahwa berhaji melalui penyelenggara negara asing adalah pelanggaran hukum negara. Konsekuensi dari pemberitahuan/pemahaman tentang tata administrasi tersebut, Dirjen Haji dan Umroh Kemenag perlu bersinergi dengan lintas kementerian dan dengan pemda agar memberi pemahaman kepada publik. Hal ini sebagai bentuk pelayanan publik oleh negara terhadap warganya secara adil dengan mengedepankan terwujudnya amanat UU Nomor 25 Tahun 2009 tentang Pelayanan Publik pada Pasal 4 (d) keseimbangan hak dan kewajiban, (g) tak diskriminatif, (l) cepat, mudah, dan terjangkau. Pasal 9 (1) dalam rangka mempermudah penyelenggaraan pelayanan publik, dapat dilakukan sistem pelayanan terpadu. Bila hal ini terlaksana maka hal ini tak akan terjadi paspor fiktif dan hal tabu, yakni calon jemaah haji tahun 2016 yang berasal dari Sumenep Madura menyobek paspor karena dikira karcis bus. Hal ini dilakukan setelah turun dari bus, ia tergabung dalam kloter Kabupaten Jember. Ada pula sambal petis bocor yang dibawa jemaah, ditemukan rokok dalam tas, tidak tahu cara memanfaatkan toilet di pesawat, dan sebagainya. 
ljtihad: Jurnal Wacana Hukum Islam dan Kemanusiaan, Volume 17, No. 2, Desember 2017: 241-259

\section{Penutup}

Pemerintah harus segera menerbitkan produk hukum berupa (1) pelarangan bagi muslim yang telah haji bila berhaji lagi dengan sanksi riil dan dipublikasikan kecuali ada faktor tertentu yang dapat ditoleransi. Menoleransinya dengan pertimbangan yang ketat, (2) memoratorium (penghentian pendaftar haji) karena rentan terjadinya korupsi bagi penyelenggara. Pada masa kini, negara melayani muslim dalam berhaji dengan UU Haji. Negara harus memfasilitasi setiap umat beragama dengan kemudahan beribadah. Hal ini sebagai bentuk pelayanan publik oleh negara terhadap warganya secara adil dengan mengedepankan terwujudnya amanat UU Nomor 25 Tahun 2009 tentang Pelayanan Publik. Pasal 4 (d) keseimbangan hak dan kewajiban, (g) tak diskriminatif, (1) cepat, mudah, dan terjangkau. Pasal 9 (1) dalam rangka mempermudah penyelenggaraan pelayanan publik, dapat dilakukan sistem pelayanan terpadu.

Di tengah persoalan paspor fiktif, yakni setelah 177 calon jemaah haji Indonesia yang berangkat via Filipina tertangkap, ternyata ada 700 orang yang sudah terlanjur lolos sampai di Arab Saudi dengan paspor Filipina sehingga mereka akan kembali ke Filipina setelah pulang dari Arab Saudi (pasca-haji). Hal ini berpeluang bermasalah lagi di Filipina. Akan tetapi, telah ada komunikasi antara Presiden Jokowi dengan Presiden Filipina Rodrigo Duterte agar 700 jemaah haji tersebut langsung kembali ke Indonesia dari Arab Saudi. Kedubes RI di Arab Saudi dan tim Kemenag mencari/mengidentifikasi 700 jemaah tersebut. Bila mereka tak teridentifikasi/tak ditemukan sehingga kepulangannya haji ke Filipina, Pemerintah Filipina tak akan memidanakan jemaah tersebut karena mereka korban penipuan. Pemerintah RI pun tak memberlakukan Pasal 23 huruf H UU Nomor 12 Tahun 2006 tentang Kewarganegaraan. Pasal itu menyebutkan seseorang kehilangan kewarganegaraan jika mempunyai paspor atau surat yang bersifat paspor dari negara asing atas namanya. Mereka tak akan kehilangan kewarganegaraan RI. Hal ini dinyatakan Menkum HAM Yasonna H Laoly saat rapat dengar pendapat dengan Komisi III DPR RI Rabu 7 September 2016 (Kompas, 8 September 2016). Agen yang memberangkatkan calon jemaah haji tersebut asal Indonesia, yakni PT Taskiah, PT Aulad Amin, PT Aulad Amin Tours Makassar, Travel Shafwa Makassar, Travel Hade El Barde, KBIH Arafah, dan KBIH Arafah Pandaan. Mereka harus diberi sanksi tegas sebagai pembelajaran sehingga timbul aspek jera pada mereka yang melanggar dan pihak lain tidak mengikutinya. 
Dinamika haji Indonesia sejak era kolonial dan problematika calon haji ilegal (Moh. Rosyid)

\section{Daftar pustaka}

Arifin, Bambang Syamsul. Psikologi Agama. Pustaka Setia: Bandung, 2008.

Atjeh, Aboebakar. Kakbah dan Perjalanannya. Ramadhani: Solo, 1993.

Azra, Azyumardi. Jaringan Ulama Timur Tengah dan Kepulauan Nusantara Abad XVII dan XVIII. Mizan: Bandung. 1998.

Ishomuddin. Pengantar Sosiologi Agama. Ghalia Indonesia dan UMM Press: Malang, 2002. Jalaluddin. Psikologi Agama. Rajawali Press: Jakarta, 2009.

Jawa Pos, Rabu 28 Juni 2017, hlm. 8. Rawan Pungli Selama Musim Haji.

Majalah Tempo edisi 5-11 September 2016.

Patuhena, M. Shaleh. Historiografi Haji Indonesia. LKiS: Yogyakarta. 2007.

Rahmah, Noer. Pengantar Psikologi Agama. Teras: Yogyakarta, 2013.

Raho, Bernard. Agama dalam Perspektif Sosiologi. Obor: Jakarta. 2013.

Ramayulis. Psikologi Agama. Kalam Mulia: Jakarta, 2009.

Rosyid, Moh. Belajar pada Ulama Nusantara yang Mendunia. Kolom Mimbar Jumat Koran Muria, 26 September 2014.

Rosyid, Moh. Keunikan Kota Makkah. Kolom Mimbar Jumat Koran Muria, 12 September 2014. 
